\title{
Grafiti: jarte que realza o denigra los monumentos arquitectónicos y la ciudad?
}

\author{
Amanda Mejía Franciscolo / Geraldine Ortega Poma \\ Universidad de Lima
}

Recibido: 28 de julio del 2018 / Aprobado: 17 de agosto del 2018

doi: 10.26439/limaq2019.n005.4535

\begin{abstract}
Actualmente, los edificios considerados patrimonio histórico no están en la atención de las nuevas generaciones. Esto da pie a que sean olvidados y muchas veces violentados con firmas hechas con spray - actos vandálicos, puesto que están prohibidos por la ley-. Pero el grafiti no solo involucra este tipo de firmas "hechas a la mala"; por ejemplo, también incluye los murales artísticos, una práctica que evoca un mensaje para el transeúnte, pero con un carácter más profesional. El presente artículo busca encontrar una manera de que ambas obras de arte - el patrimonio histórico y los grafitis - alcancen una relación armoniosa y sean complementarias. Para lograrlo, es necesario crear una serie de parámetros que regulen la intervención artística.
\end{abstract}

grafiti, expresión, ilegalidad, arte callejero, mural, identidad, patrimonio histórico, monumento, arquitectura, regulación

\section{Graffiti: art enhancing or denigrating architectural monuments and the city?}

Nowadays, buildings considered to be historic heritage are not under the eyes of new generations, which would result in falling them into oblivion and being several times damaged by spray-painted signatures: vandalisms since they are forbidden by the law. However, graffiti does not only imply these "careless" signatures. For example, it also includes artistic murals, a practice which communicates a message for passers-by with a more professional nature. This paper seeks to find the way in which both works of art - historic heritage and graffiti - reach a harmonious relation and complement each other. To achieve this, it is necessary the creation of a series of parameters to regulate the artistic intervention.

graffiti, expression, illegality, street art, mural, identity, historic heritage, monument, architecture, regulation 


\section{INTRODUCCIÓN}

El grafiti o arte callejero es una práctica muy extendida en la ciudad contemporánea, genera un gran impacto en la sociedad y da nuevos significados al espacio público. Los productores hacen notoria la afirmación de su identidad, sus denuncias, protestas, homenajes y emociones, además de registrar hechos para formar una memoria colectiva. Este artículo discute brevemente la frontera entre el grafiti como arte y como transgresión de lo privado, así como lo que significa su realización en una zona monumental, donde el patrimonio arquitectónico parece haber sido olvidado. En ese sentido, se recurre a distintos argumentos a favor y en contra de este tipo de manifestaciones: ¿pueden convivir armoniosamente el arte callejero y los monumentos arquitectónicos?

En primer lugar, para indagar hasta qué punto el grafiti es socialmente aceptado y cuáles son los límites para su elaboración, llevamos a cabo una distinción entre grafiti o arte callejero y arte mural o grafiti regulado. Se parte de la la hipótesis de que, si se ve al grafiti como un acto marginal y se enfatiza su ilegalidad, se va a llegar a la conclusión de que es una amenaza para el patrimonio y el bien común. En cambio, si es visto desde una perspectiva más artística, puede ser aceptado por su valor estético y usos sociales a partir de la institucionalización de la práctica. En cuanto a esta última, se encontró información sobre el riesgo de que en estos espacios regulados se pierdan las características de anonimato y espontaneidad del grafiti; además, puede darse que el contenido también sea controlado. Esto último implicaría que no se puedan realizar las denuncias antes mencionadas.
Centrándonos en el arte mural, se plantea la hipótesis de que logra realzar los monumentos arquitectónicos siempre y cuando se involucre a una serie de profesionales relacionados al tema y se siga una serie de pautas para lograr ser pertinentes con el contexto. Se ve la necesidad de crear una serie de parámetros que regulen la intervención para que no sean pautas o recomendaciones arbitrarias, sino que cuenten con un sustento y el apoyo de todos los interesados. Cabe aclarar que la producción de este tipo de grafiti en zonas monumentales no es una salida para evitar la restauración del patrimonio o su reactivación a través de la inserción de nuevos usos.

\section{METODOLOGÍA}

Para llevar a cabo esta investigación, se recurrió a distintos artículos científicos. En primer lugar, para hablar de los posibles orígenes de las pinturas murales, se revisó el trabajo de Cristóbal Campana, que data del año 2005 y refiere a la historia del término grafiti y sus manifestaciones en Lima. Luego, se escogieron artículos que relatan cómo, por qué y dónde surgió el grafiti, además de definirlo y clasificarlo en distintos tipos. Estas publicaciones se enfocan en el periodo comprendido entre los años sesenta y noventa en el contexto norteamericano. Se revisaron también documentos más recientes para tener un acercamiento a la problemática contemporánea, en los que figuran las opiniones de distintos sociólogos, se genera un debate entre las diferentes corrientes de pensamiento y se dan ejemplos con estudios de caso en Valparaíso, Quito y Bogotá.

En la segunda parte del trabajo, se tomó como muestra lo acontecido en el centro histórico 
del Callao, ahora llamado Callao Monumental. Se recurrió a reportajes y documentales de Panamericana, América Televisión y TV Perú, así como a una serie de noticias al respecto en los periódicos El Comercio, La República y Diario 21. Además, se realizó una rápida encuesta a las personas que residen y trabajan en el centro histórico del Callao. Las preguntas realizadas se encuentran en la sección "Anexos".

También se entrevistó a algunos especialistas relacionados directamente con este tipo de intervención artística y con el patrimonio para conocer su postura crítica. Primero, a Aldo Lértora, arquitecto restaurador y profesor en la Universidad Ricardo Palma y la Universidad de Lima. Luego, a la historiadora del arte Paloma Carcedo, quien fue subgerente de Patrimonio Cultural,ArtesVisuales, Museos y Bibliotecas de la Gerencia de Cultura de la Municipalidad de Lima en el periodo 2011-2014.

Se contactó, además, al bachiller en arquitectura Bryan Castillo, profesional que reside en el Callao, interesado en las intervenciones artísticas que se han estado dando a raíz del proyecto Fugaz. Asimismo, Angie Pelosi, administradora de este proyecto, respondió el teléfono; sin embargo, no se logró obtener respuesta suya a las preguntas realizadas por correo (véase la sección "Anexos").

Se recabó información fotográfica sobre el caso de estudio: los murales más representativos y el encuentro de otros que cuentan una realidad distinta (murales retrato realizados por El Salsa Dklle).

No se llegaron a confirmar las entrevistas con los artistas icónicos e iniciadores de estos festivales, principales autores de las intervenciones dadas en el centro histórico del Callao: Entes (Joan
Jiménez Suero) y Pésimo (Edwin Higuchi Hernández).

\section{RESULTADOS}

La Real Academia de la Lengua Española (2018) define grafiti como 'firma, texto o composición pictórica realizados generalmente sin autorización en lugares públicos, sobre una pared $\mathrm{u}$ otra superficie resistente'. Equivale a incluir en el espacio público un pensamiento mediante dibujos (murales) o frases que puedan generar discusión con el ciudadano. Puede evocar finalidades políticas, conocimientos, memorias comunes o diferencias ideológicas. No solo expresa rebeldía, sino también emociones positivas, como el amor o el humor.

No está dentro de lo que llamamos "arte público", puesto que este último es una propuesta estatal que engloba un arte ordenado y financiado por el mismo Estado o Municipalidad. Como ejemplo de esto, se pueden mencionar la pintura mural y la escultura monumental que se caracterizan por ser colocadas no necesariamente donde el público las necesita, sino en lugares donde contrastan con la identidad local, por lo que las personas no desarrollan un vínculo con estas exhibiciones. En cambio, por varios años, el grafiti ha sido considerado una "marca urbana relacionada con lo prohibido" (Gama-Castro y León-Reyes, 2013, p. 361), caracterizado por la marginalidad, el anonimato y la espontaneidad.

Para profundizar más sobre el tema, históricamente, esta expresión pudo tener base en las pinturas rupestres. Los primeros seres humanos relataban su vida cotidiana mediante murales que los arqueólogos denominaron grafiti. Siguiendo la línea temporal, encontramos en Egipto los jeroglíficos en monumentos, 
tumbas y esculturas; aquellos eran considerados muy importantes por ser el lenguaje de los dioses (Hilliard, 2015). Son hasta ahora valiosos, pues representan las historias y vivencias de esa sociedad y sus deidades. Siglos después, en Europa del Renacimiento, se observa el paso de las pinturas en paredes de catedrales y palacios importantes. El arte es expresado de manera distinta, se dota de técnicas y era objeto de estudio perfeccionarlas.

Es así como, a lo largo de la historia, se refleja la necesidad innata de expresión de nuestra especie, desde la descripción de actividades como la caza y la recolección en el paleolítico hasta llegar a ser un modo de crítica a la sociedad y a la política, como lo que el grafiti ahora representa.

El origen del término grafiti, tal como lo conocemos ahora, surgió a finales de los sesenta y principios de los setenta en las comunidades afroamericanas de Queens, Bronx y Brooklyn (Estados Unidos). Era expresión de la marginación social y de una voluntad de presencia fisica en la ciudad. Primero aparecieron a manera de firmas o tags, que eran como una marca de territorialidad, y a principios de los ochenta se intensificó esta expresión y se diversificaron sus formas - una de las destacadas fueron las plantillas o stencil- (Ballaz, 2009).

Esta práctica, entendda como ilegal por darse en la clandestinidad, se produjo en espacios abandonados y lugares con falta de vigilancia. Se debe considerar que, al ser practicada en lo oculto, muchos artistas que crecieron alrededor de este arte consideran que a mayor riesgo al hacer el grafiti, mejor es la obra resultante. También consideran que es una manera de alzar su voz frente a los problemas sociales para que estos no sean ignorados (Ballaz, 2009).
En la actualidad, esta práctica no siempre es considerada una forma de vandalismo. En varias ciudades, el grafiti es promovido y reconocido como arte, es apoyado por instituciones públicas o privadas e incluso es realizado con la previa autorización de los propietarios del inmueble, principalmente por el carácter mercantil que ha ido adquiriendo poco a poco al ser usado para promover el turismo. Es en estos casos que hablamos de grafiti regulado; no suele mostrar oposición a las ideologías dominantes y puede estar ligado a dinámicas de producción y consumo capitalistas (Araya López, 2015).

Esta institucionalización ocurre en zonas de tolerancia, festivales, teatro, galerías, concursos escolares, entre otros eventos, en los que se le reconoce su valor social y artístico. El término zona de tolerancia se refiere a la creación de espacios para que los productores del grafiti puedan expresarse "libremente" (Araya López, 2015). El riesgo en estos espacios es que se pierdan las características antes mencionadas: la marginalidad, el anonimato y la espontaneidad del grafiti. Además, puede suceder que el contenido también sea controlado o no refleje realmente la identidad de la zona en la que se realiza (Ferrell, 1993; Austin, 2001). Aclaremos que este "grafiti regulado" es en realidad un tipo de pintura mural que usa la técnica del grafiti.

Se tiene como evidencia, por ejemplo, que artistas famosos como Banksy lograron popularidad por el impacto de sus grafitis. Sus obras son tan admiradas que la misma sociedad toma una posición distinta y les da el lugar de una expresión de arte que vale la pena reconocer, principalmente por los mensajes que transmiten y la gran habilidad que evidencian. La particularidad de este autor es que muchas veces sus producciones no cuentan con autorización 
y aun así son aceptadas por la mayoría. Por ello, a pesar de que ahora sea criticado por poner a la venta su arte y ganar dinero a través de él, Banksy sigue haciendo grafiti tanto legal como ilegal, adaptando su propio contexto para expresarse, creando stencils y demás pinturas para intervenir la normalidad con que funciona la sociedad.

Sin embargo, aunque el grafiti cuente con más apoyo, prevalece el ser considerado "inferior" a cualquier otro tipo de expresión artística apoyada por el academicismo, e incluso "contracultural", posiblemente porque cuestiona los espacios establecidos para hacer arte y exhibirlo, y porque suele ser hecho por jóvenes que carecen de estudios sobre arte. Debido a esto, aún existen tensiones y conflictos entre grafiteros y artistas callejeros, autoridades municipales, habitantes de la ciudad y el sector privado. Cada uno de ellos define lo que es válido y lo que no según sus propios intereses (Araya López, 2015). Es por ello que varios autores cuestionan los límites de esta práctica, de lo legal e ilegal, así como también lo que se entiende por cultura, arte y patrimonio. Mencionamos este último porque suele implicar medidas de protección y conservación que pueden verse transgredidas por las manifestaciones del arte callejero.

Entonces nos hacemos la siguiente pregunta: ¿será posible la convivencia armoniosa entre el arte callejero y la arquitectura? O más interesante aún, ¿entre el arte urbano y los monumentos arquitectónicos? Hay quienes dicen que sí, que las manifestaciones artísticas ligadas a una arquitectura obsoleta han logrado darles nuevos usos a esos espacios y han reactivado zonas antes "muertas". Otros, en cambio, insisten en que en una zona monumental no deberían realizarse este tipo de prácticas, para dar el correcto mantenimiento de los monumentos y porque significa una enorme falta de respeto. Según Araya López, esto último va a depender mucho de las motivaciones de los productores para llevarlas a cabo y del contexto en el que son elaboradas, pues existen diversos tipos de grafiti y no es posible generalizar o simplificar estas intervenciones. En algunos casos pueden ser creados con motivos políticos, estéticos, emotivo-afectivos; en otros, se orienta a la búsqueda de adrenalina (Ferrell, 1993), asociada también a una "economía de prestigio" (Austin, 2001). En cualquiera de estos casos, los autores a favor del grafiti consideran a sus productores como una forma de público subalterno y no como "inferiores", "poco educados" o personas “carentes de espacios de expresión”. Según lo que afirman, una firma anónima en un monumento público puede ser vista como una "falta de educación", pero también es posible entender ese mismo acontecimiento como un rechazo a una "historia oficial y pseudocompartida" que debería representarnos a todas y todos, pero que realmente no lo hace (Araya López, 2015, p. 93).

Aquellos en contra del arte callejero en zonas patrimoniales seguramente tienen en mente aquellos monumentos sucios, llenos de grafiti y basura, que además se ven descuidados por el paso del tiempo y las condiciones climáticas. Efectivamente, en algunos casos, los personajes ilustres (políticos, libertadores, artistas, etcétera) inmortalizados en piedra o bronce pasan los días siendo ignorados por las personas e incluso han sido objeto de vandalismo, ya sea con dibujos o escritos inapropiados,como con mutilaciones y robos (Araya López, 2015, p. 98). De esta forma, el grafiti es interpretado como el producto de una población que es indiferente al patrimonio y a la "historia común". Sin embargo, también es cierto que esta conclusión no toma en cuenta 
el evidente rechazo a una idea de identidad, herencia e idiosincrasia que quizá ya no es válida en un contexto contemporáneo. El sociólogo Araya López afirma que el hecho de que la gente escriba su nombre en una superficie urbana invita a la reflexión sociológica de si los espacios urbanos actuales son formas solidificadas de exclusión de aquellos que son desconocidos, sin mérito, invisibles. Así, plantea la siguiente pregunta: ¿por qué son solamente los "ciudadanos ilustres" quienes son inmortalizados en el espacio fisico urbano? La idea de una ciudad que es "edificada como un museo" y que, por tanto, no permite la libre expresión y espontaneidad para transformarla o modificarla, es cuestionada por diversos autores a partir de nociones como el derecho a la ciudad.

Por otro lado, existe aún una visión de corte criminógena y epidemiológica del grafiti. Resulta sencillo decir "el que raya paredes hoy, asalta gente mañana", pero este argumento puede resultar simplista, ya que ha sido fácilmente refutado por especialistas que afirman que establece relaciones causales que solo pueden comprobarse a partir de datos e información científica, y no a partir de figuras retóricas o de estrategias argumentativas. Un ejemplo de ello es considerar estas intervenciones no como vandalismo sin significado alguno, sino como un acto de desobediencia civil con un propósito mayor que permite la desconexión temporal de las nociones morales (que habitualmente impedirían su realización). Esto es parte de las técnicas de neutralización que la criminología crítica considera como válidas, ya que dicho acto no implica que los participantes vayan a convertirse en asaltantes u homicidas, sino que se apela a causas mayores que en cierto modo justifican sus acciones.
Si se ve al grafiti como un acto vandálico y se enfatizan su impacto en el orden público y la seguridad, definitivamente se va a llegar a la conclusión de que es una amenaza para el patrimonio y el bien común. En cambio, el grafiti en su forma más artística puede ser aceptado socialmente por su valor estético y usos sociales a partir de la institucionalización de la práctica (Araya López, 2015). Es por eso que esta discusión va más allá de lo que es arte y lo que no. Tomando como supuesto que se realicen murales considerados artísticos, ¿dónde, cómo y con qué criterios se deben realizar? ¿Será posible un consenso con el mismo gobierno o las autoridades que permita este arte de manera verdaderamente libre? Pero al hacerlo perdería su esencia máxima, que usualmente es la protesta ante las carencias que existen. Por otro lado, el grafiti no solo involucra problemática, sino también una respuesta del ciudadano al redescubrir su espacio y hacerlo más suyo plasmando algo de él. Una posible solución sería una regulación específica que indique el permiso para producir murales únicamente si colaborarían con la educación y expresión de sus generaciones. Quizá si se hallan los parámetros precisos para cada lugar que ayuden a los artistas a comprender la identidad de cada contexto para expresarse sin ser tildados de vándalos, se pueda lograr una revolución cultural en el espacio público, que brinde un arte tan antiguo y valioso al alcance de la ciudadanía y su futuro.

\section{CASO DE ESTUDIO: CALLAO MONUMENTAL}

Para lograr responder estas interrogantes, se investigó el caso del centro histórico del Callao, llamado Callao Monumental. En el año 2011, el empresario israelí Gil Shavit compró la casa 


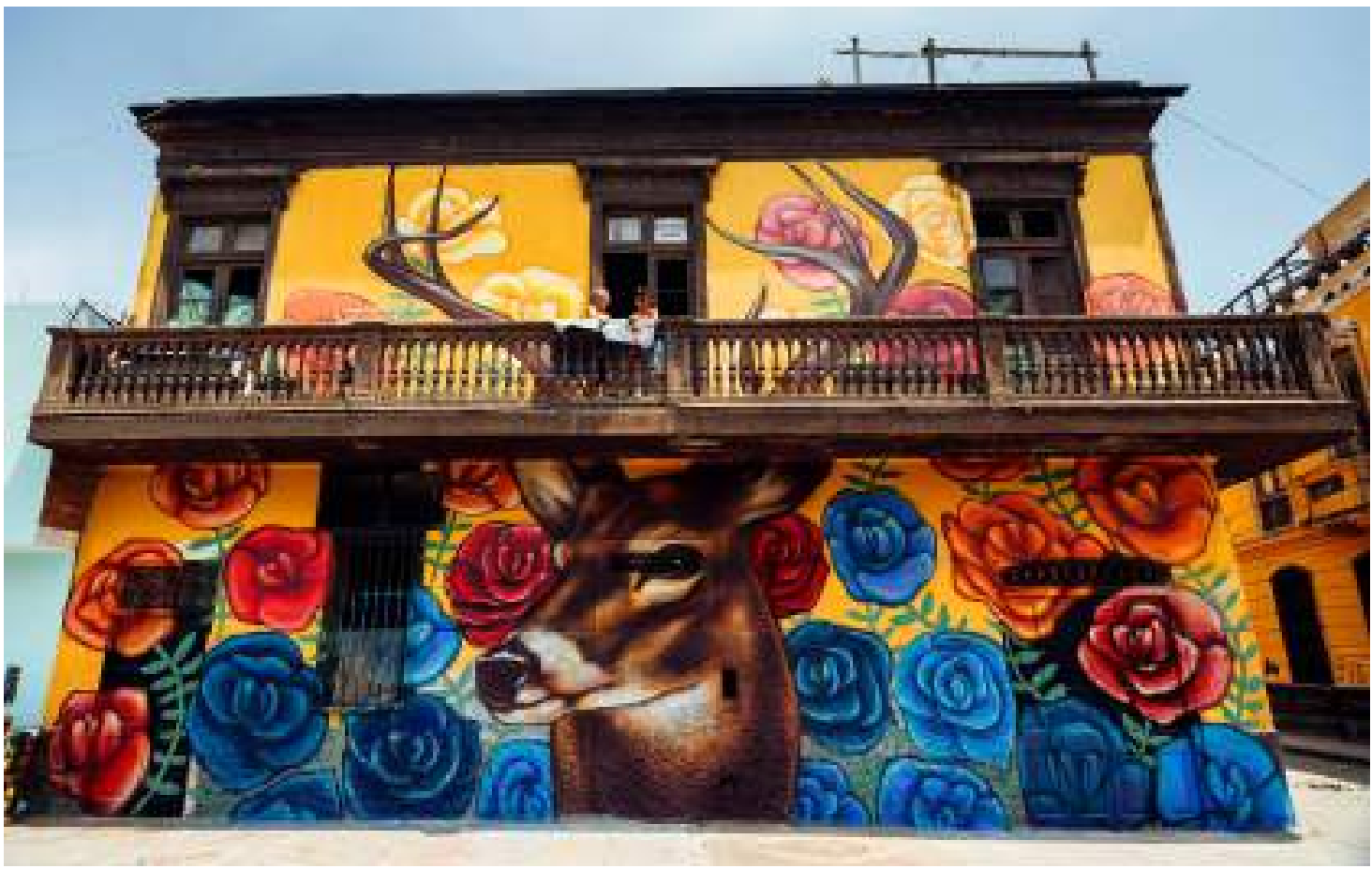

Figura 1. Mural de venado con flores. Casona en el barrio Castilla, 2016

Fuente: archivo fotográfico de las autoras

Ronald, un edificio inglés construido entre 1900 y 1928 en pleno centro histórico del Callao. En el 2015, Gil se unió con Isabel Miró Quesada para llevar a cabo el proyecto Fugaz, que buscaba combatir la violencia con arte. Para ello, se restauró la Casa Ronald, en donde ahora se albergan galerías de arte, escuelas, talleres, salas de exposiciones y restaurantes (Callao: Proyecto Fugaz, 2016).

En marzo del 2016, y como resultado de que el Callao Monumental empezó a ser un centro artístico, se realizó en las calles chalacas el festival de arte urbano Latidoamericano, organizado por Entes y Pésimo. Dicho festival tuvo como invitados a artistas de diferentes partes del mundo para realizar coloridos murales (figura 1). El bachiller arquitecto Bryan Castillo, en un artículo suyo, da a conocer su postura crítica sobre el escaso criterio en ciertos murales hechos incluso en monumentos históricos. Argumenta que este evento tuvo una anterior edición en el centro histórico de Lima y tuvo mejores resultados; es decir, no se cuestionó el cuidado del patrimonio, el mensaje que transmitían los murales o la vulneración de la identidad del lugar. Al término del festival en el Callao, se continuaron realizando murales bajo la dirección del proyecto Fugaz. Es preciso 
resaltar que cuentan con la autorización de la Dirección Desconcentrada de Cultura, la Municipalidad Provincial del Callao y el Gobierno Regional del Callao. Se debe considerar, además, que estos murales hacen uso de la técnica del grafiti, pero no son grafiti en el sentido estricto de la palabra.

La problemática encontrada en el centro histórico del Callao es que el patrimonio, tanto material como inmaterial, se ha visto afectado, lo que ha generado un debate respecto al real aporte de estos murales, si se deben continuar realizando o no (Castillo, 2017). Muchos de los edificios intervenidos son monumentos, se encuentran dentro de una zona monumental o ambiente urbano monumental. Esto quiere decir que poseen un valor artístico e histórico en sí mismos que el grafiti sobrepuesto desmerece. Al pintar murales sobre las fachadas de antiguas casonas no solo se atenta contra el Reglamento Nacional de Edificaciones, entre otras normas oficiales, sino que se da el errado mensaje de que estas adquieren valor en ese momento, como si se estuviera pintando sobre un lienzo en blanco (figuras 1, 2 y 4).

Sobre este tema, el arquitecto restaurador Aldo Lértora afirma que el tipo de intervención pertinente debería ser algo efimero (no permanente), y da como ejemplo el espectáculo de luces hecho en la fachada de la catedral de Notre Dame, en París. Los colores y fachadas cambiantes dinamizan el edificio y lo activan. $\mathrm{Si}$ se dieran este tipo de intervenciones momentáneas en los edificios olvidados por la población, habría resultados positivos y quizá hasta más convenientes que con los murales. En cuanto a estos últimos, argumenta que podrían funcionar en zonas deprimidas como una revaloración momentánea para generar interés; pero que, a la larga, le quitan autenticidad al edificio, ya que al ser una obra de arte (mural) plasmada en él, este se distorsiona tanto artística como urbanísticamente. Esta conversación brindó a nuestra investigación la perspectiva de una forma de intervención sin restar los valores arquitectónicos de los edificios del centro histórico. Junto con ella, otras actividades culturales, como la música y los bailes, podrían generar revalorización y concientización.

Por otro lado, la historiadora del arte Paloma Carcedo comenta que lo que ocurre en el Callao es que no se protege el centro histórico y se está deteriorando mucho. Lo ideal es que se restaure, que el Estado invierta dinero para que las personas lo usen y paseen por ahí. Sin embargo, la falta de presupuesto no lo permite y, si la Municipalidad no da incentivos al sector privado para su renovación, apoyar las intervenciones con grafiti es una mejor opción que dejarlo abandonado. Concuerda con las personas que afirman que las pinturas murales no tienen por qué estar en ese lugar ya que allí se encuentran la iglesia y los monumentos; pero, si no hay otra opción, prefiere mil veces eso porque se le da vida a la zona. Comenta, además, que hay otras opciones para la restauración, que no se tiene que gastar tanto dinero conservando el interior del monumento cuando este ya no funciona. Basta con conservar la fachada y el resto puede ser totalmente nuevo, de modo que se ahorra así un mantenimiento constante. En cuanto a los edificios que no son patrimonio, la historiadora afirma que no hay normativa municipal que prohíba la elaboración de murales sobre sus fachadas y que, además, si se elaboran en esquinas abandonadas o zonas grises y oscuras, pues resultan ser un gran atractivo que reactiva la zona. 
La visita al centro histórico del Callao, entonces, fue productiva en el sentido de que se detectó que las pinturas murales, si bien atraen la atención de las personas, no pueden funcionar solas: el edificio abandonado o en pésimas condiciones tiene que ser restaurado y estar en uso público en la primera planta; de lo contrario, por más murales que se realicen, la zona va a seguir descuidada y la sensación de peligro por los pasajes y las calles anexas a la iglesia matriz persistirá. Esto sucede con el monumento abandonado frente a la plaza Gálvez, sobre el cual Entes y Pésimo realizaron grafitis vistosos y coloridos; sin embargo, no se obtuvieron los resultados esperados (figuras 2 y 4 ).
A partir de este claro ejemplo en el caso de estudio, se puede decir que uno de los criterios para pintar un mural dentro de una zona monumental o centro histórico es elegir bien la ubicación de este, cuál sería el lienzo por usar. Se pueden realizar, por ejemplo, en un muro ciego o alguna pared medianera, de manera que no atente contra el valor arquitectónico de ningún edificio, tal como ocurrió en el festival Latidoamericano en el centro histórico de Lima.

A continuación, dos ejemplos de grafiti en comparación: el primero sobre el monumento en mención de la plaza Gálvez (figura 3) en contraste con otros dos que se realizaron en muros ciegos (figuras $2,4,5$ y 6 ):

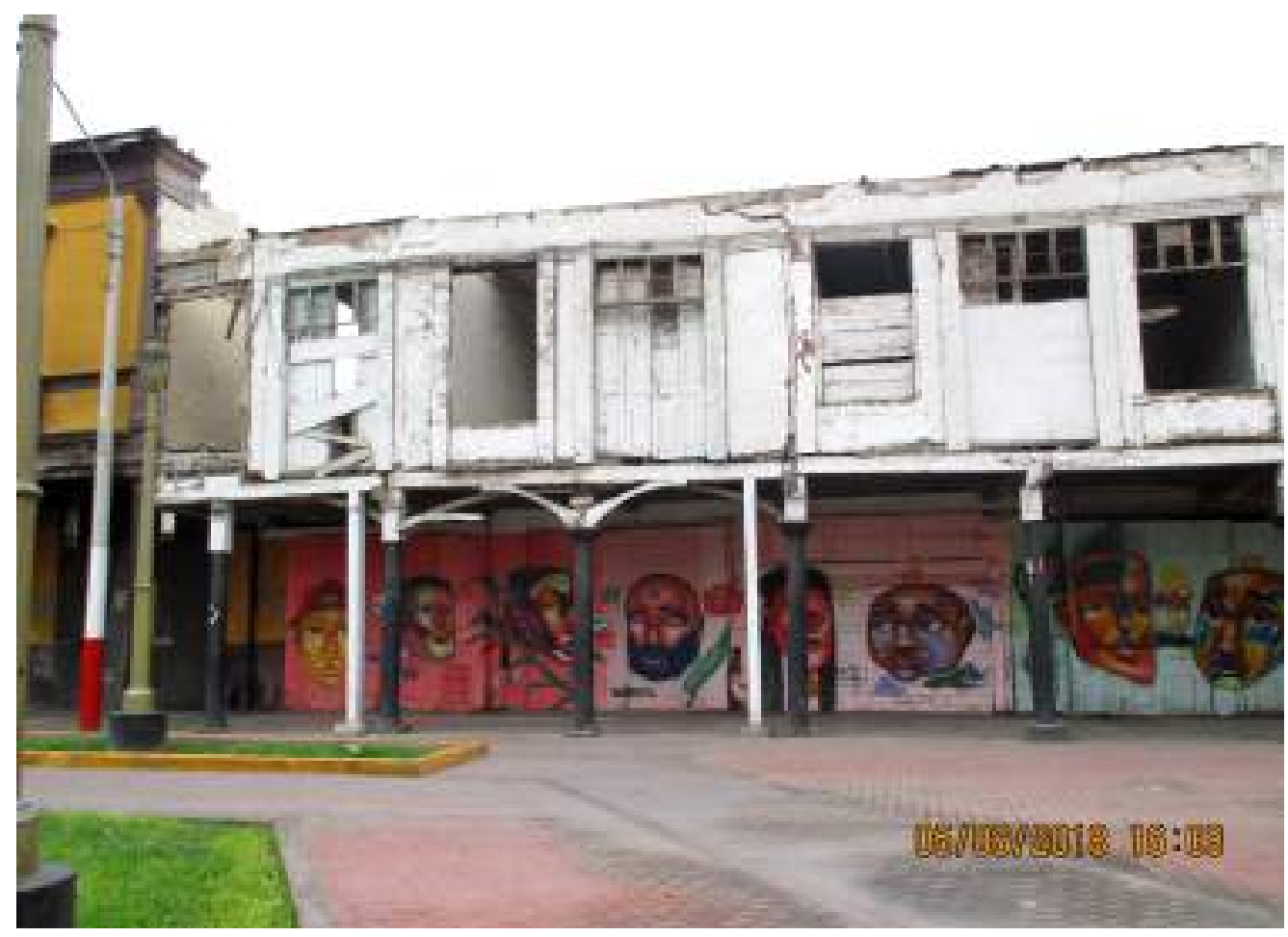

Figura 2. Grafiti de rostros aleatorios hecho por Entes y Pésimo. Casona frente a plaza Gálvez, 2018

Fuente: archivo fotográfico de las autoras 


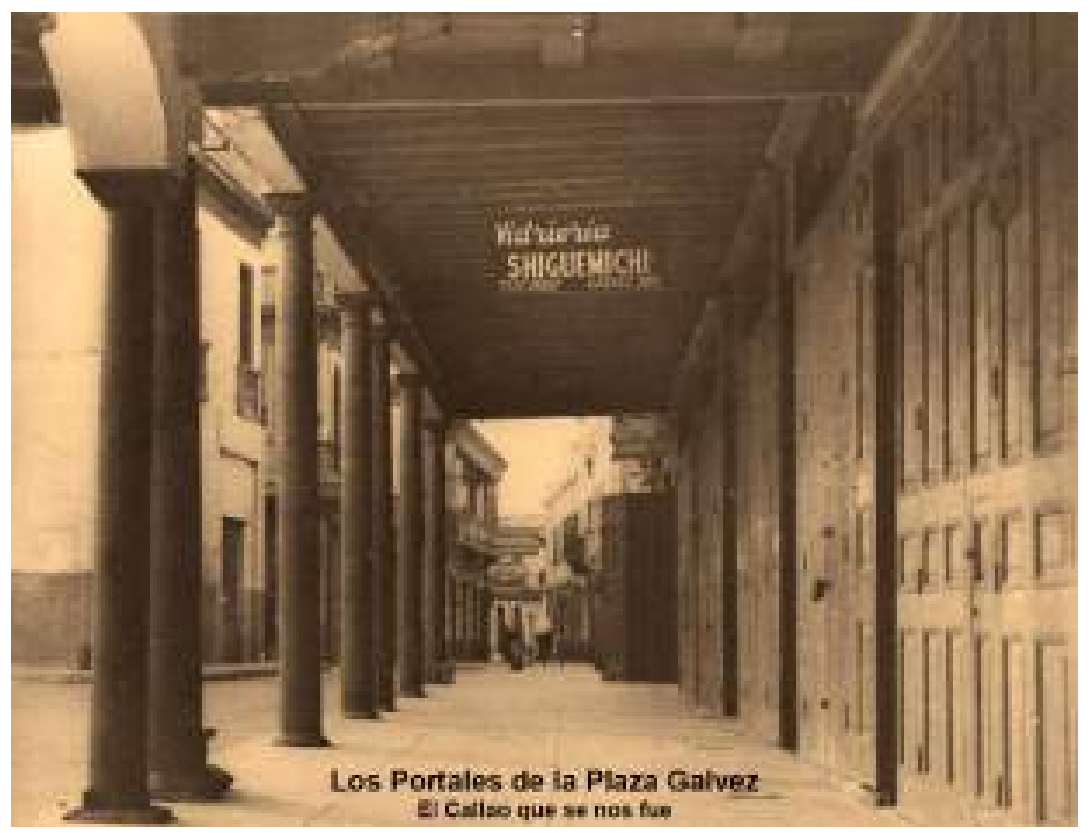

Figura 3. Portales de la plaza Gálvez en décadas pasadas, sin intervención Fuente: El Callao que se nos fue, 2017a

Figura 4. Portales de la plaza Gálvez, pero ya intervenidos. Mantienen el mismo problema de antes: la inactividad.

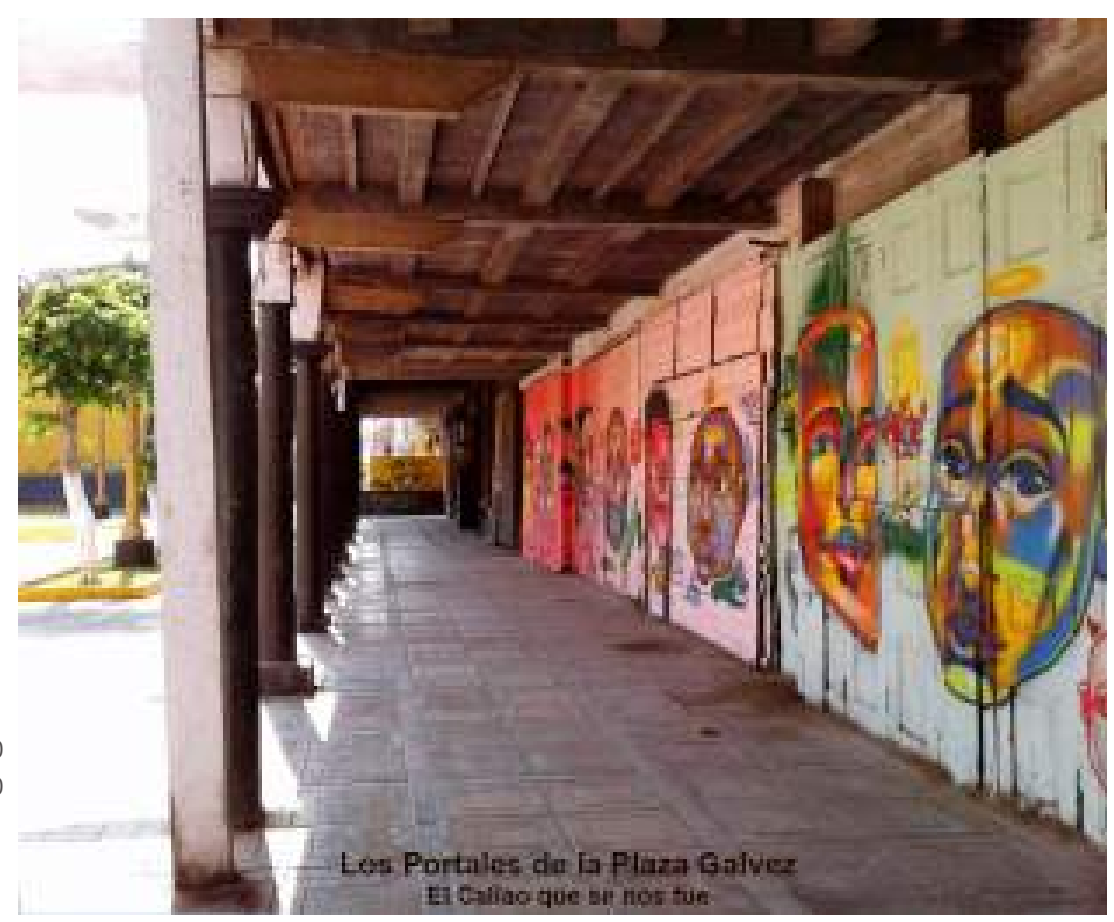

Fuente: El Callao que se nos fue, 2017b 
Figura 5. Vista de un grafiti tag 0 firma. Desarmoniza el conjunto arquitectónico. Calle Miller, lateral a la iglesia matriz, 2018

Fuente: archivo fotográfico de las autoras
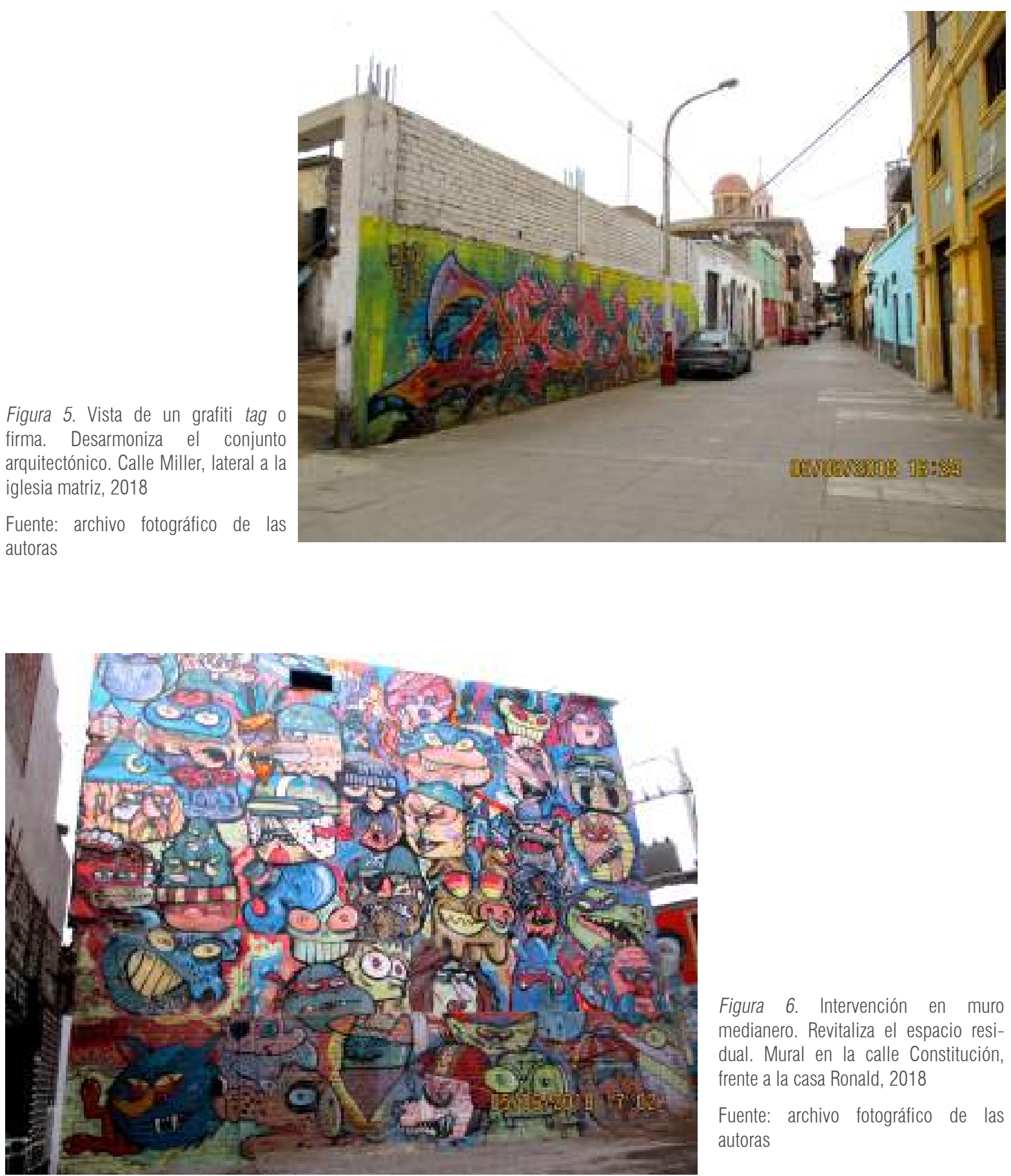

Figura 6. Intervención en muro medianero. Revitaliza el espacio residual. Mural en la calle Constitución, frente a la casa Ronald, 2018

Fuente: archivo fotográfico de las autoras 
Uno de cada tres vecinos no se siente identificado con el patrimonio arquitectónico, por lo que sí está a favor de los murales, sin importar su ubicación. Las personas defienden y cuidan lo que les pertenece, lo que conocen: los murales deben reflejar su identidad (figuras 7, 8 y 9); es así que entra a tallar la pertinencia de la temática de estos. En las entrevistas, dos de cada tres residentes no entienden el significado de los murales o no encuentran relación entre estos y el lugar en donde viven. Existe, pues, un claro problema de identidad que no se resuelve con los murales equivocados. Esto no quiere decir que se debe limitar el contenido a solo costumbres y personajes del lugar, sino que las obras no pueden ser hechas aleatoriamente y sin pensar qué transmitirá en el lugar donde se realizan. Se podría, por ejemplo, mostrar la realidad multicultural del Perú y, de cierta manera, educar o hacer reflexionar.

Sin embargo, existen opiniones en contra de lo que se está proponiendo en este punto de la investigación. La historiadora Paloma Carcedo, por ejemplo, nos indica que a un grafitero no le puedes decir que pinte sobre un tema porque deja de ser grafiti, deja de ser espontáneo. La idea del grafiti en la calle es pintar velozmente y salir corriendo. Es un mensaje rápido, directo, fácil de entender y se borra una vez que haya cumplido su función. En cuanto a los murales permitidos por la Municipalidad, tampoco se puede limitar al artista, ya que este es libre: cada uno tiene un estilo propio, por eso es tan íntimo. Nos comenta que a veces el artista ni lo piensa: lo hace porque le gusta y no tiene por qué dar algún mensaje necesariamente; aunque, por lo general, buscan dar uno en las zonas más deprimidas, de modo que dejan su protesta. Todo depende del lugar, el momento, el artista, etcétera.

A continuación, se muestran algunos ejemplos que sí respetaron la identidad del lugar, muy aparte de respetar o no el patrimonio.

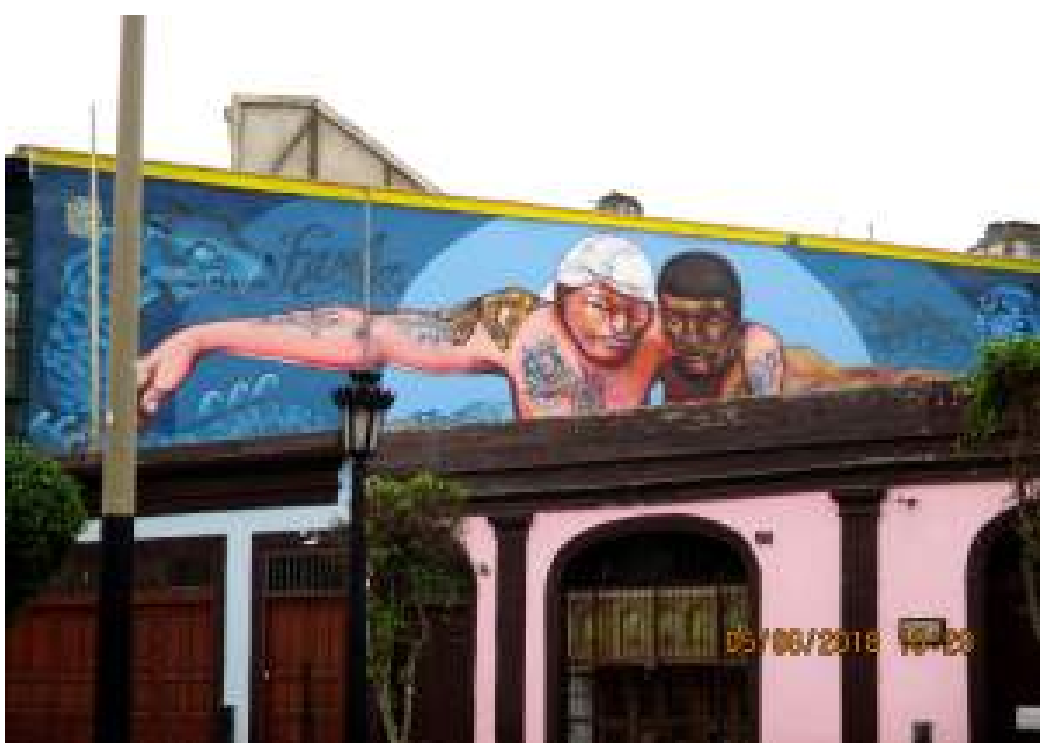

Figura 7. Mural en muro medianero, dedicado a la familia chalaca, hecho por Entes y Pésimo. Casa en la plaza matriz, 2018

Fuente: archivo fotográfico de las autoras 


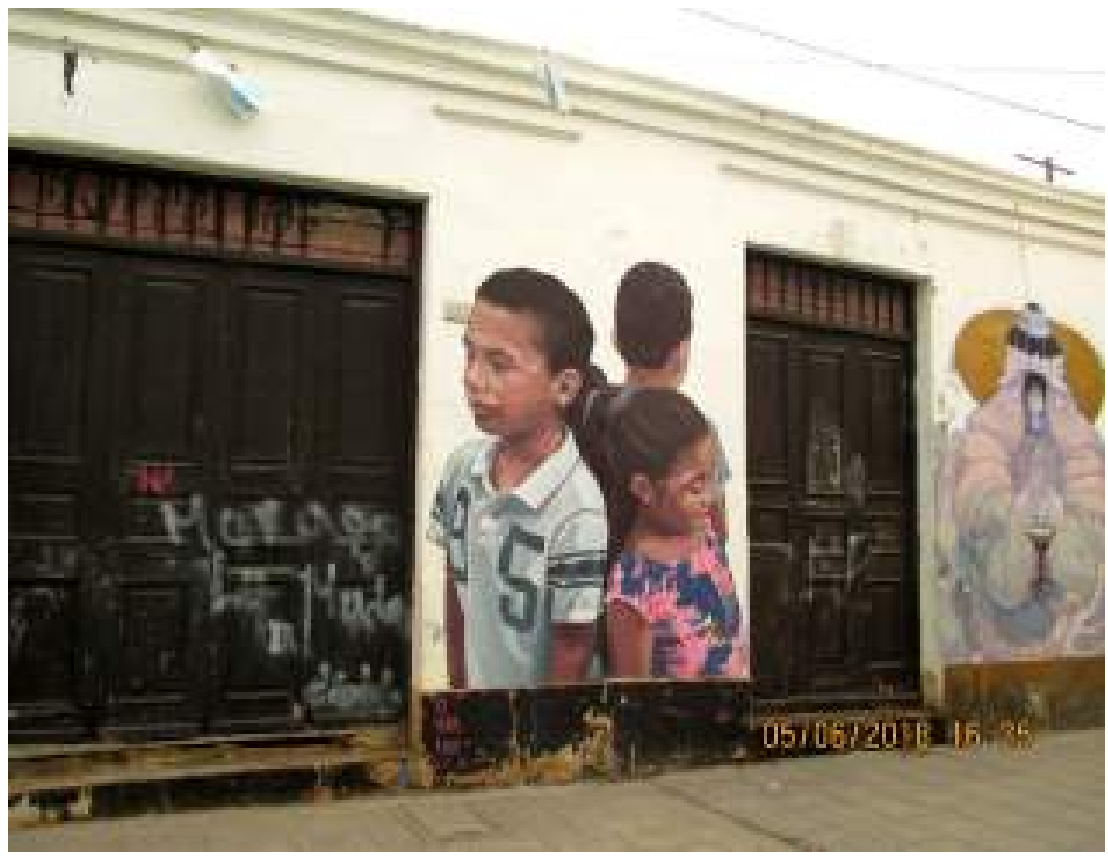

Figura 8. Mural que expresa identidad: representación de los niños chalacos. Calle Independencia, 2018

Fuente: archivo fotográfico de las autoras

Figura 9. Mural en dos partes que toca el tema de la identidad: representación de un vecino chalaco. Plaza matriz, 2018

Fuente: archivo fotográfico de las autoras

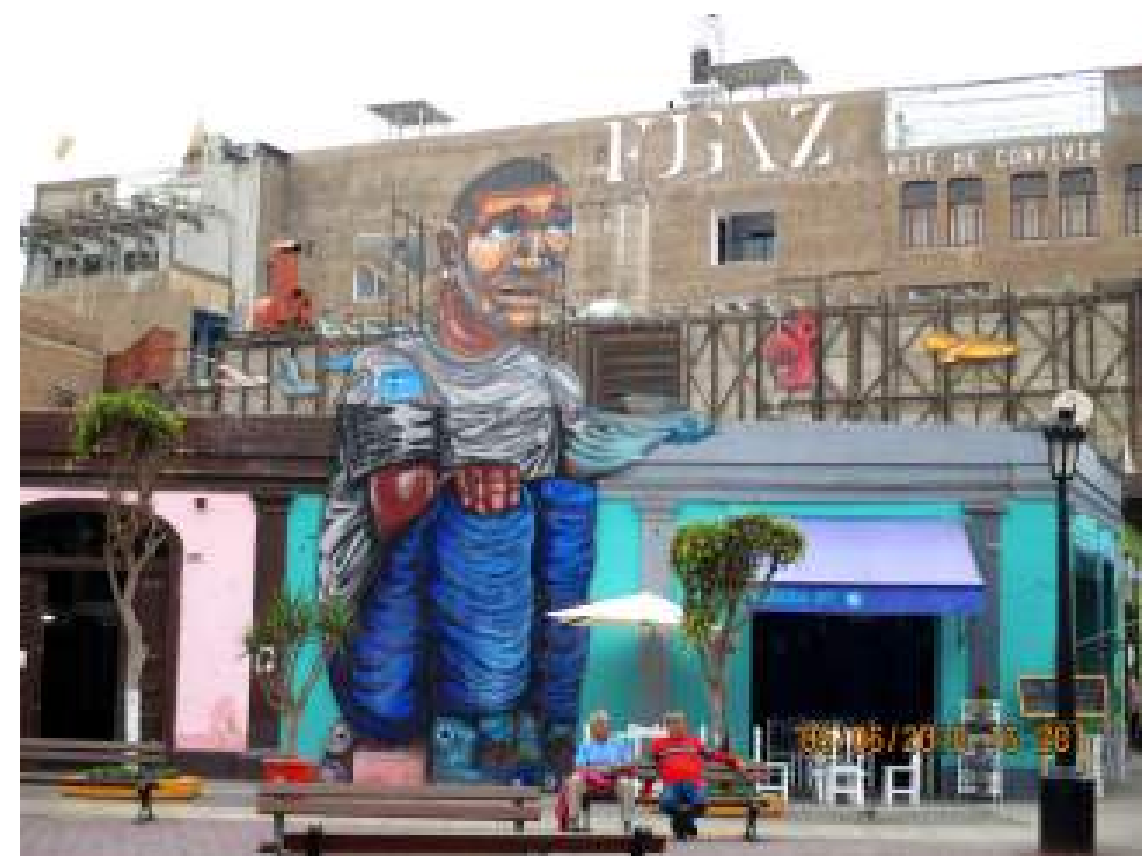


Se encontró también otro tipo de murales, pintados esta vez por el artista El Salsa DKlle, uno de los más conocidos del Callao. Su grafiti expresa netamente retratos de chalacos, en su mayoría víctimas de la delincuencia (figura 11). A continuación, una imagen del mural mejor trabajado de este artista (figura 10). Se trata de un personaje que cualquiera puede identificar netamente como chalaco, pues representa una de las actividades más importantes del puerto del Callao: el tejido de redes para la pesca. Expresar en la totalidad del inmueble este personaje quien es, por cierto, vecino chalaco y padre del muralista - revive la calle donde se sitúa; sin embargo, como se mencionó anteriormente, para conservar la actividad del lugar es importante que exista un uso comercial o cultural que haga de su recorrido una necesidad.

Figura 10. Un pescador hecho por el muralista chalaco El Salsa Dklle. El inmueble en que está este mural no es de valor monumental. Centro histórico del Callao

Fuente: Castillo, 2017

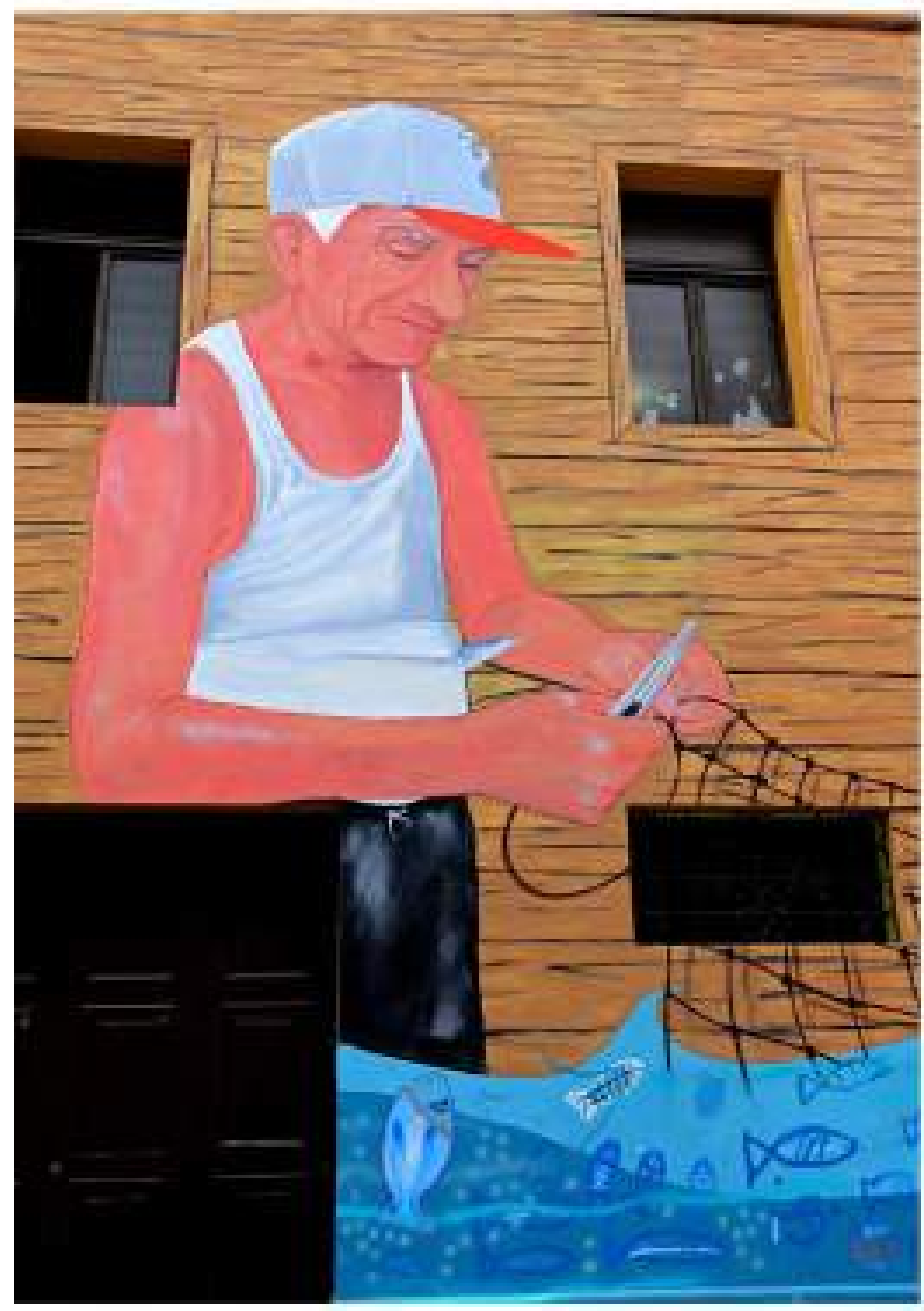




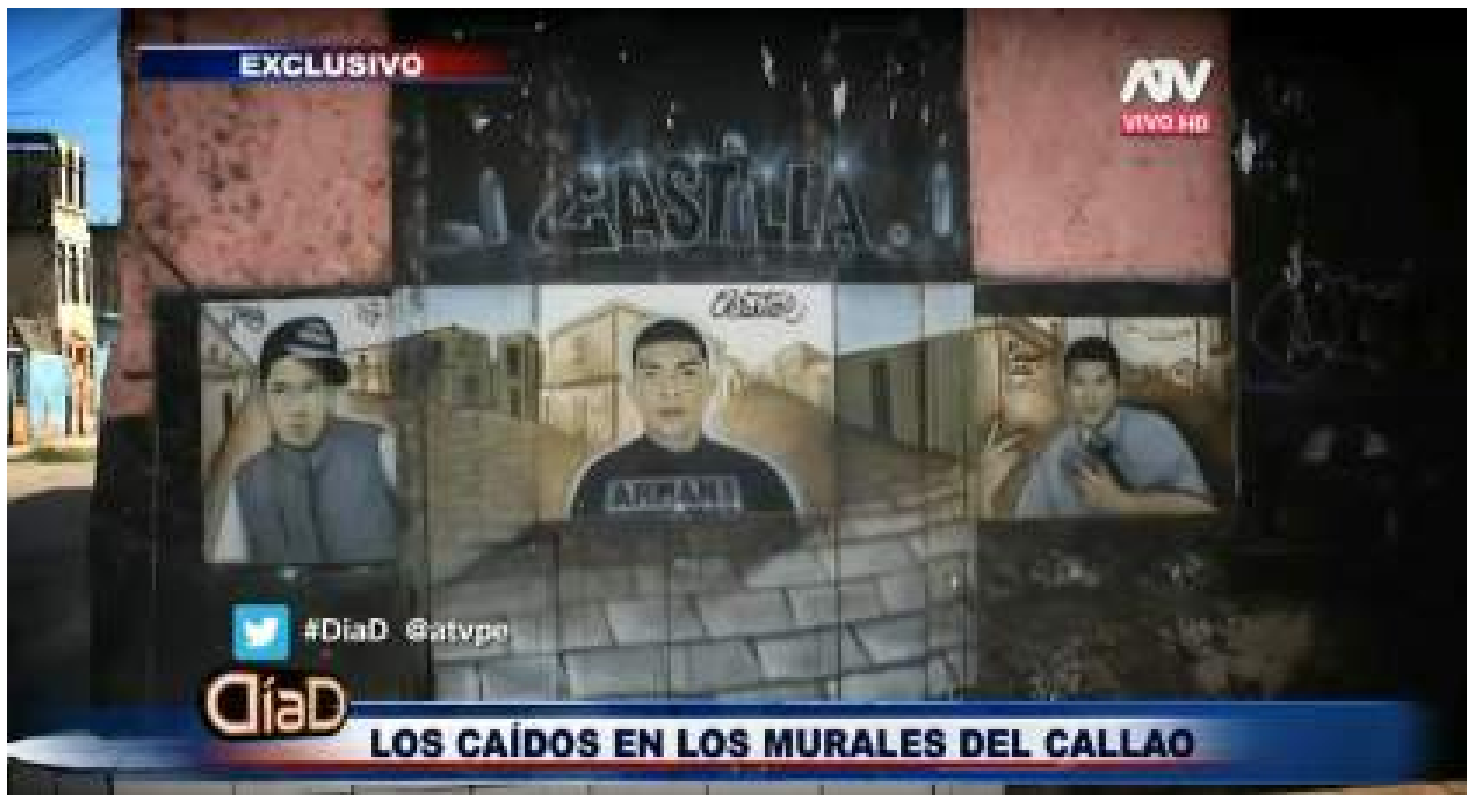

Figura 11. Jóvenes asesinados en las calles aledañas. Retratos realizados por El Salsa DKIlle.

Fuente: Día D, 2016, 8:48

Otras obras conocidas en el Callao Monumental son estos tres retratos, también pintados por El Salsa Dklle (figura 11). Este tipo de mural tiene la capacidad de transmitir la realidad de un lugar, es interesante porque refleja una problemática social que debe ser solucionada: la alta delincuencia. Cabe recordar que el Proyecto Fugaz quiso reducir el índice de delincuencia brindando al Callao arte y recuperando edificios. Sin embargo, es importante destacar que se debería abarcar más allá del centro histórico, ya que las calles anexas a este son, en su mayoría, inseguras a toda hora del día y mucho más por las noches.

Otro criterio importante es, entonces, la pertenencia al lugar. Si se es un vecino de la zona, evidentemente se contará con el apoyo de todos los que ahí viven y se logrará plasmar con mayor exactitud las necesidades, las costumbres, las tradiciones, los anhelos, etcétera, de la población. Pero no se deben dejar de lado los criterios anteriores.

Finalmente, se puede hablar de un criterio mucho más subjetivo: la calidad del producto artístico. Esta puede ser determinada según la aprobación de la mayoría una vez realizado el mural; sin embargo, para prever un buen resultado, es mejor que el artista siga ciertas pautas académicas, que tenga la experiencia suficiente en trabajos preliminares, en caso de no ser un profesional. Y tener el respaldo constante de un especialista en patrimonio, curadores, historiadores y críticos de arte. 


\section{DISCUSIÓN}

Hace falta un nexo de los vecinos con su patrimonio arquitectónico y el arte mural puede ser el mediador de este vínculo. Para ello, se debe seguir una serie de pautas para evitar fracasos en las posteriores intervenciones. El ideal es que, tanto vecinos como artistas, especialistas, autoridades y empresarios que subvencionen las intervenciones puedan trabajar en conjunto.

El caso de estudio brinda información para establecer los parámetros de las obras artísticas (murales), de modo que puedan dar su mensaje y expresarse sin transgredir ni la identidad del usuario que vive en la zona ni la arquitectura, la cual también se considera arte que merece respeto. Llegamos a la conclusión de que los proyectos de esta envergadura deben ser incluidos por la Municipalidad en la fase de planificación de las intervenciones del espacio público para generar un conversatorio con los distintos especialistas en patrimonio e historia y los artistas que intervendrán con su arte en el centro histórico. Además, es importante que los vecinos sean parte de los procesos que se dan y participen en mesas de diálogo, puesto que son los principales interesados en aquello que ocurre en sus calles.

También es necesario que se respete tanto el Reglamento Nacional de Edificaciones para intervenir en zonas monumentales como lo acordado por el Ministerio de Cultura. No puede haber una contradicción en este sentido, como ocurre en el Callao, donde la Dirección Desconcentrada de Cultura, la Municipalidad Provincial del Callao y el Gobierno Regional del Callao han autorizado la elaboración de grafitis sobre monumentos arquitectónicos sin un buen sustento.
La creación de parámetros específicos —que ordenen el tipo de edificio, el contexto, el método de intervención y el mensaje por plasmar- hará que el encuentro entre patrimonio histórico $\mathrm{y}$ arte mural funcione de la manera correcta, respetándose, revalorizándose y reactivándose, pensando en la gente y su cultura.

\section{REFERENCIAS}

Araya López, A. (2015). Discusiones sobre las prácticas del graffiti en el periódico $\mathrm{La}$ Nación (2001-2010). Revista Ciencias Sociales, (150), 91-108.

Austin, J. (2001). Taking the train. How graffiti art became an urban crisis in New York City. Nueva York: Columbia University Press.

Ballaz, X. (2009). El graffiti como herramienta social. Una mirada psicosocial a las potencialidades críticas del arte urbano. En I. Márquez Alonso, A. Fernández Liria y P. Pérez-Sales, Violencia y salud mental (pp.132-144).Madrid:Asociación Española de Neuropsiquiatría.

Callao: Proyecto Fugaz lleva arte para combatir la inseguridad. (6 de marzo del 2016). El Comercio, p. 1.

Campana,C.(15dediciembredel2005).Losgraffiti de Lima: ¿gesto artístico o acto vandálico? Recuperado de http://cristobalcampana. com/attachments/article/2/Graffiti_Arte_ o_Vandalismo.pdf

Castillo, B. (2017). Cuando el arte vulnera la identidad de un lugar. Recuperado de http://www.larana.pe/2017/04/cuandoel-arte-vulnera-la-identidad-de.html 
Día D. (20 de marzo del 2016). Los caídos retratados en Los Murales del Callao [archivo de video]. Recuperado de https:// youtu.be/rWnA7iXHhD4

El Callao que se nos fue. (20 de mayo del 2017a). Los Portales de la Plaza Gálvez en el Callao (antes y después de la Administración del «Chim Pum Callao»). Digitalizado por: Ricardo Gonzales Zapata. Aporte de: El Callao que se nos fue [actualización de estado en Facebook]. Recuperado de https://www.facebook. com/ElCallaoQueSeNosFue/photos/a.69 2295160839222/1335829819819083/?ty $\mathrm{pe}=3 \&$ theater

El Callao que se nos fue. (20 de mayo del 2017b). Los Portales de la Plaza Gálvez en el Callao (antes y después de la Administración del "Chim Pum Callao»). Digitalizado por: Ricardo Gonzales Zapata. Aporte de: El Callao que se nos fue [actualización de estado en Facebook]. Recuperado de https://www. facebook.com/ElCallaoQueSeNosFue/ photos/a.692295160839222/133582982315 $2416 /$ ?type $=3 \&$ theater

Ferrell, J. (1993). Crimes of style. Urban graffiti and the politics of criminality. Nueva York: Garland Publishing.

Grafiti. (2018). En Diccionario de la lengua española [versión en línea]. Recuperado de https://dle.rae.es/?id=JPvdsiL

Hilliard, B. (1 de mayo del 2015). Jeroglíficos egipcios: el lenguaje de los dioses. Recuperado de https://www.ancientorigins.es/artefactos-escritos-antiguosnoticias-general/jerogl $1 \%$ C3\%ADficosegipcios-el-lenguaje-los-dioses-002474

\section{BIBLIOGRAFÍA}

Buenos Días Perú. (22 de abril del 2016). Callao: popular barrio de Castilla nos muestra su nuevo rostro (1/2) [archivo de video]. Recuperado de https://www.youtube. $\mathrm{com} /$ watch? $\mathrm{v}=90 \mathrm{R} u$ 9urzDLM

Collazos, O. (1989). El graffiti, un arte democrático. Comunicación, 1(67), 63-65.

Daniels, J. I. (2016). Intervenciones en la calle, intervenciones en el aula: el arte urbano quiteño. Hispania, 99(2). Recuperado de http://www.jstor.org/stable/44112860

Día D. (20 de marzo del 2016). Los caídos retratados en Los Murales del Callao [archivo de video]. Recuperado de https://www. youtube. $\mathrm{com} /$ watch? $=\mathrm{rWnA7iXHhD} 4$

Gama-Castro, M. M., y León-Reyes, F. (2013). Bogotá, arte urbano o graffiti. Entre la ilegalidad y la forma artística de expresión. Arte, Individuo y Sociedad, 28(2), 355-369.

La Mula Reportajes. (6 de diciembre del 2016). ¿Qué está pasando en Monumental Callao? [archivo de video]. Recuperado de https://www.youtube.com/watch? $v^{=}$ ljpJyaDGOM

Pereda, J. (2006). Nuevos lugares de intención: intervenciones artísticas en el espacio urbano como una de las salidas a los circuitos convencionales. Estados Unidos 1965-1995. Universidad Complutense de Madrid.

Sin Filtros. (9 de noviembre del 2016). Gentrificación: Mi barrio está de moda / Sinfiltros.com [Reportaje de Sin Flitros]. Poder [archivo de video]. Recuperado de https://www.youtube.com/watch?v= a4zIqonyVOg 
Stornaiolo Pimente, U., y Ortega Salinas, R. (2014). El graffiti contemporáneo como expresión creativa cultural. Quito: Universidad Central de Ecuador.

Suazo,M.V.(s.f.). Graffiti y arte callejero:tensiones en torno a la intervención del espacio público y privado en la ciudad de Valparaíso (20102014). Recuperado de http://docplayer. es/45389209-Graffiti-y-arte-callejerotensiones-en-torno-a-la-intervencion-delespacio-publico-y-privado-en-la-ciudadde-valparaiso.html
TV Perú.(15 de diciembre del 2016). Costumbres - Callao en su punto - 13/12/2016 [archivo de video]. Recuperado de https://www. youtube.com/watch?v $=\mathrm{Xr} 8 \mathrm{sVA}$ 5T2RY

24 horas. (4 de marzo del 2016). Callao: peligroso barrio de Castilla cambia de rostro gracias al arte [archivo de video]. Recuperado de https://www.youtube. $\mathrm{com} /$ watch? $\mathrm{v}=\mathrm{HbV} \_$SGgkd04

Victor Sendic Angulo Torres (2016). Callao tomado por el arte. Cuarto Poder [archivo de video]. Recuperado de https://www. youtube.com/watch? $\mathrm{v}=\mathrm{NnWlP} 1 \mathrm{UtNeM}$ 


\section{ANEXOS}

\section{Encuesta a las personas que residen y trabajan en el centro histórico del Callao}

1. ¿Usted cree que la inserción de los murales en el centro histórico del Callao sea positiva? (señalando la plaza matriz donde se sitúa la iglesia).

2. ¿El turismo incrementó?

3. ¿La delincuencia disminuyó?

4. ¿Se identifica o entiende la intención de los murales?

5. ¿Le gustaría seguir encontrando este tipo de arte en las calles del Callao?

Entrevista vía correo electrónico a Angie Pelosi, administradora del proyecto Fugaz, Callao Monumental:

1. ¿Cómo y por qué fue que nació este proyecto? ¿Quiénes colaboraron y siguen colaborando en él?
2. ¿Se han obtenido los resultados esperados? Es decir, ¿cómo va el proyecto ahora, qué está pasando actualmente en el Callao? Sabemos que se está dando trabajo a los vecinos de la zona $-\mathrm{y}$ nos parece algo muy positivo-, entre otros beneficios a los chalacos.

Por otro lado, vimos en un reportaje que el objetivo de Fugaz era lograr que la delincuencia disminuya.

3. ¿Qué tanto ha disminuido? ¿Se tienen datos cuantitativos al respecto?

Evidentemente, es ahora una zona de fácil acceso para todo público, cuando antes era un barrio que nadie quería pisar porque se decía que era muy peligroso.

4. ¿Cuál es el verdadero radio de influencia de Fugaz?

La semana pasada estuvimos en los alrededores de la iglesia matriz y la plaza Gálvez y varios vecinos de la zona nos preguntaban qué hacíamos ahí y nos recomendaban que nos marcháramos. Esto sucedió incluso en calles en donde había murales. 
